\title{
Hypertonic saline for acute viral bronchiolitis: take the evidence with a grain of salt
}

\author{
Jürg Barben ${ }^{1}$ and Claudia E. Kuehni
}

\begin{abstract}
Affiliations: 'Division of Paediatric Pulmonology, Children's Hospital of Eastern Switzerland, St Gallen, Switzerland. ${ }^{2}$ Paediatric Epidemiology, Institute of Social and Preventive Medicine, University of Bern, Bern, Switzerland.
\end{abstract}

Correspondence: Jürg Barben, Paediatric Pulmonology and Allergology, Children's Hospital of Eastern Switzerland, $\mathrm{CH}-9006$ St Gallen, Switzerland. E-mail: juerg.barbenđakispisg.ch

O

@ERSpublications

We can improve future studies by agreeing on a definition of acute viral bronchiolitis for large, multicentre RCTs http://ow.ly/zrZhP

Fifty years ago, ReYNOLDS and СоOK [1] wrote, "Oxygen is vitally important in bronchiolitis and there is little convincing evidence that any other therapy is consistently or even occasionally useful." Their claim is once again supported by the new trial on hypertonic saline published in this issue of the European Respiratory Journal (ERJ) [2].

Acute viral bronchiolitis (AVB) is the most common lower respiratory tract infection in infancy. It is caused by respiratory viruses, typically by respiratory syncytial virus [3]. Although only $1-2 \%$ of children are hospitalised, AVB accounts for a large proportion of paediatric emergency visits and hospitalisations during winter months [4]. An effective treatment would reduce the number of hospitalisations, hospital length of stay (LOS) and their corresponding health costs.

Over the past half century, no therapy for AVB has shown a convincing effect, though many have been tested. Among those treatments ruled out are $\beta_{2}$-agonists, anticholinergics, inhaled or oral corticosteroids and chest physiotherapy [5-8]. Adrenaline might slightly improve short-term outcomes in outpatients but does not seem to reduce LOS in in-patients [9]. Current management recommendations and guidelines thus focus on supportive treatment with supplemental oxygen, fluid management, nasal douche with normal saline and/or nasal decongestants and respiratory support as needed, and avoiding unnecessary handling [10-14].

Recently, studies have investigated the effectiveness of nebulised hypertonic saline. The first results looked promising [15-18]. A Cochrane review, which included papers indexed in medical databases until May 2013 [15-25], concluded that nebulised 3\% hypertonic saline may reduce LOS among infants with nonsevere acute bronchiolitis, and improves clinical severity scores among in- and outpatients [26]. Unfortunately, the studies included in the review are heterogeneous and sample sizes are generally small. The type of interventions varied: some inhaled hypertonic saline only once or twice [19, 25] while others used repeated inhalation until discharge. Intervals between inhalations varied from 4 to $8 \mathrm{~h}$; inhaled volumes varied between 2 and $5 \mathrm{~mL}$. Type of nebuliser [15, 16, 21, 22, 25] and mass median aerodynamic diameter [15, 16] were rarely mentioned. Only a few studies tested hypertonic saline as a monotherapy. Most added other drugs regularly or on demand, including adrenaline $[15,16,18-20,24,25]$ or $\beta_{2}$-agonists $[17,18,21,23,25]$. Criteria for hospital admission, oxygen requirement and discharge differed between studies, and oxygen saturation cut-off varied. All but one study [18] came from a single centre. Some focused on in-patients

Received: July 162014 | Accepted: July 172014

Conflict of interest: None declared.

Copyright @ERS 2014 
$[15,16,18,21,22,24]$, others on outpatients [17] or emergency department visitors [19, 20, 23, 25]. Most studies included children with moderate-to-severe bronchiolitis; three focused on milder disease [17, 21, 25].

Since the publication of the Cochrane review, four more studies on hypertonic saline in AVB have been published [2, 27-29]. Overall, their results were disappointing. A single-centre study from Memphis, TN, USA, showed no improvement in clinical severity score, admission rate or LOS [27]. A randomised controlled trial (RCT) of 62 patients from Cleveland, OH, USA, reported more respiratory distress in patients treated with hypertonic saline and no effect on hospitalisation rates [28]. The trial by Wu et al. [29] from Los Angeles, CA, USA, with 408 patients, found that those treated with hypertonic saline had lower admission rates than those treated with normal saline (29\% versus $43 \%)$ but there was no effect on LOS (3.9 versus 3.2 days). The latest study, by TeUniSSEN et al. [2], published in this issue of the ERJ, is the second largest to date and the only true multicentre study. It included 247 patients from 11 general hospitals and one tertiary centre in the Netherlands. The authors compared two concentrations of hypertonic saline (3\% and 6\%) with normal saline. The study was conducted carefully, in young infants (average age 3.4 months). It had clear inclusion criteria: children with possible asthma (previous wheeze, allergy or response to one dose of salbutamol) were excluded. The primary outcome was LOS, defined as the time between the first dose of medication and the decision to discharge. The study found that LOS was comparable between treatment groups, with a tendency for longer stays in patients who received hypertonic compared to those who received normal saline. Secondary outcomes (need for supplemental oxygen or tube feeding, and Wang score) were also similar between groups. Once these new studies are integrated in the systematic review, results for hypertonic saline are likely to be just as disappointing as those for all other tested drugs.

How can we explain the contradictory results of all these studies? First of all, it is likely that infants and toddlers who wheeze with a viral infection suffer from a spectrum of disorders. Differences in pathophysiology between groups might cause differences in response to the same treatment [30]. There is no internationally accepted definition of AVB. When studies use different criteria to diagnose an illness and select their subjects, it is difficult to compare them. For example, in the UK, AVB is defined as a "a seasonal viral illness characterised by fever, nasal discharge and dry, wheezy cough, with fine inspiratory crackles and/or high pitched expiratory wheeze on examination" [3, 13]. Australian and Swiss definitions are comparable to the British definition, but emphasise youth $(<12$ months $)$ and first episode, and the importance of crackles, which are closely correlated with disease severity [12, 31, 32]. Pathology samples in such young infants show inflammation of the respiratory and terminal bronchioles, with oedema, mucus production, necrosis of epithelial cells, and only possibly some degree of bronchospasm [33, 34]. The fine crackles are caused by the "popping open" of these small airways in late inspiration. In the USA, the first appearance of wheeze (and not crackles) after an upper respiratory tract infection is considered fundamental for diagnosing AVB and the definition is not confined to the first year of life [35]. US studies of treatment of AVB included children aged up to 2 years with a first episode of wheezing, who may have had a first manifestation of asthma, triggered by a virus $[30,36]$. In these children, the main pathology lies in less peripheral airways, with bronchospasm playing a greater role. Comparing trials is difficult when researchers define AVB differently and when the phenotypes of first-time wheezers vary so widely. Under these conditions, it is no surprise that studies show conflicting results.

Second, many earlier studies were small. Inclusion criteria and outcome measures were often poorly defined, and other drugs, such as salbutamol, adrenaline or nasal decongestants, were concomitantly administered. Some of these added therapies themselves have unclear effects. For example, the role of nasal douche with saline or of nasal decongestants in bronchiolitis is unclear, and no studies have been conducted on that topic. This is particularly relevant for young infants, who are predominantly nose breathers. The effectiveness of a novel treatment is difficult to determine when it is used in combination with other untested drugs.

To reduce heterogeneity and improve the quality of future research, we suggest that future studies on the effect of existing or new drugs on AVB satisfy minimal criteria (table 1). It is essential to agree on a definition of AVB that allows us to distinguish more homogeneous subgroups within the broad group of preschool wheezers and to test if response to treatment differs between these subgroups. Subgroups could be defined by consensus among experts, based on clinical observations and evidence from pathology and pathophysiology. Given the discrepancies between European/Australian definitions and those used in the USA, the effort to craft a universal definition should be truly international, for instance by a European Respiratory Society/American Thoracic Society task force. To assist the distinction of relevant subgroups, statistical clustering methods like those used to define phenotypes in pre-school wheeze could be applied [37-39]. A meta-analysis of individual-patient data could re-examine existing datasets and test if the variability of results is explained by the different phenotypes of included infants. Findings from such secondary analyses could then be formally tested in future trials. 
TABLE 1 Proposed criteria for future therapeutic studies in infants with acute viral bronchiolitis (AVB)

Clear definition of the disease entity or entities to be studied

Study design

Clear intervention

Clear outcome measures

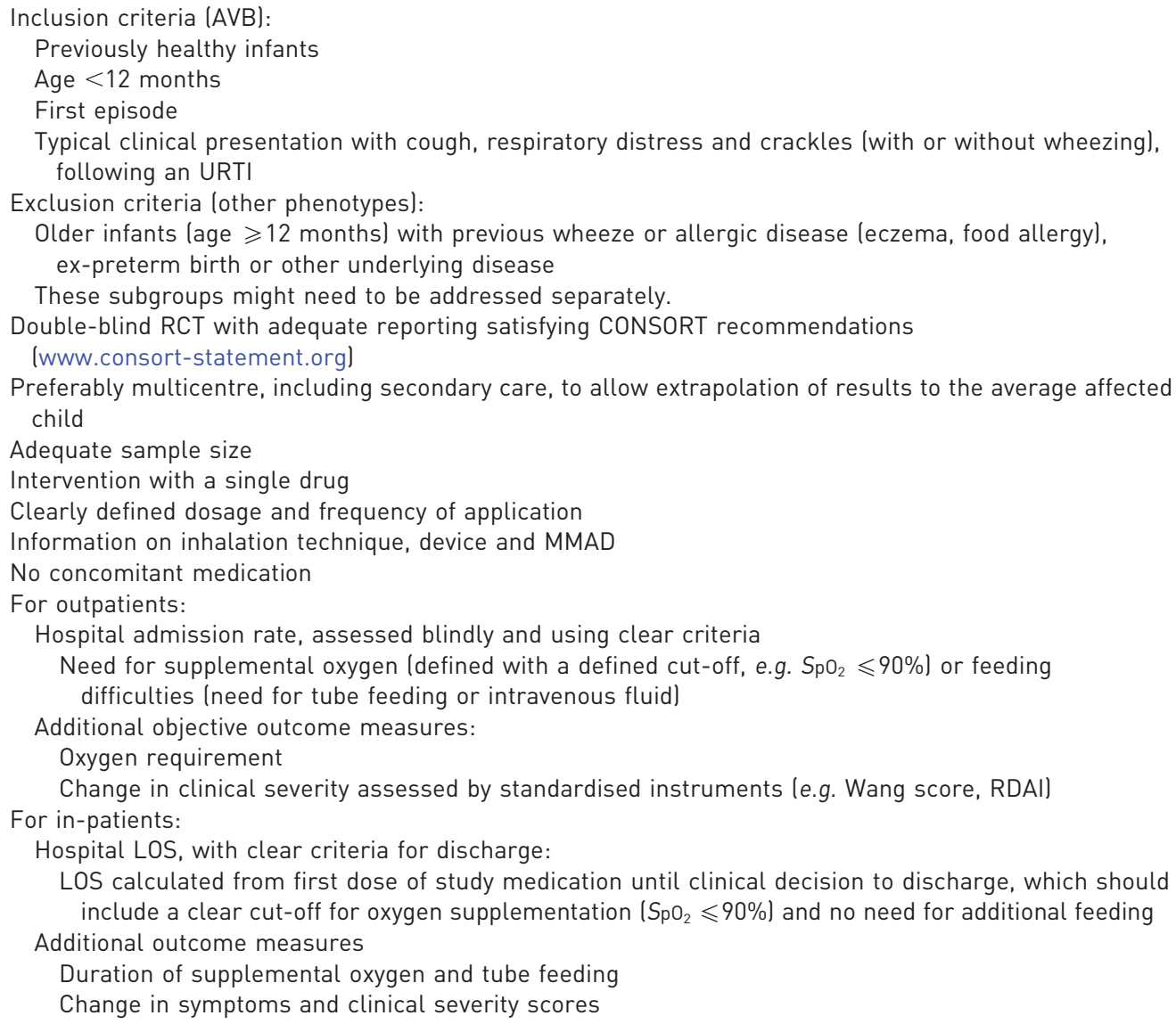

URTI: upper respiratory tract infection; RCT: randomised controlled trial; CONSORT: Consolidated Standards of Reporting Trials; MMAD: mass median aerodynamic diameter; $\mathrm{SpO}_{2}$ : oxygen saturation measured by pulse oximetry; RDAl: Respiratory Distress Assessment Instrument; LOS: length of stay.
We also recommend that future studies be designed as large RCTs and that they follow the CONSORT (Consolidated Standards of Reporting Trials) recommendations (www.consort-statement.org). They should be performed in infants who represent the target population. Multicentre studies that include both secondary and tertiary care hospitals are preferable. Inclusion and exclusion criteria and outcome measures must be clearly defined. Interventions should use a single drug and standardised administration, and avoid concomitant use of additional medications.

The current evidence does not suggest that any treatment, including hypertonic saline, provides more than a marginal benefit for infants with AVB. Best practice has not changed very much since REYNOLDS and COOK [1] made their claim: supply supplemental oxygen and proceed with supportive care, and avoid exposing patients to harmful or ineffective therapies [14]. We can only improve the quality of future therapeutic studies by coming to agreement on a strict definition of AVB and conducting large, multicentre RCTs that meet the highest standards.

\section{Acknowledgements}

We thank John Massie (Dept of Respiratory Medicine, Royal Children's Hospital, Melbourne, Australia) and Kali Tal (Institute of Social and Preventive Medicine, University of Bern, Bern, Switzerland) for lively discussions and editorial assistance.

\section{References}

1 Reynolds EO, Cook CD. The treatment of bronchiolitis. J Pediatr 1963; 63: 1205-1207.

2 Teunissen J, Hochs AHJ, Vaessen-Verberne A, et al. The effect of $3 \%$ and $6 \%$ hypertonic saline in viral bronchiolitis: a randomised controlled trial. Eur Respir J 2014; 44: 913-921.

3 Smyth RL, Openshaw PJ. Bronchiolitis. Lancet 2006; 368: 312-322. 
Hall CB, Weinberg GA, Iwane MK, et al. The burden of respiratory syncytial virus infection in young children. N Engl J Med 2009; 360: 588-598.

5 Everard ML, Bara A, Kurian M, et al. Anticholinergic drugs for wheeze in children under the age of two years. Cochrane Database Syst Rev 2005; 3: CD001279.

6 Fernandes RM, Bialy LM, Vandermeer B, et al. Glucocorticoids for acute viral bronchiolitis in infants and young children. Cochrane Database Syst Rev 2013; 6: CD004878.

Gadomski AM, Scribani MB. Bronchodilators for bronchiolitis. Cochrane Database Syst Rev 2014; 6: CD001266.

Roqué i Figuls M, Giné-Garriga M, Granados Rugeles C, et al. Chest physiotherapy for acute bronchiolitis in paediatric patients between 0 and 24 months old. Cochrane Database Syst Rev 2012; 2: CD004873.

9 Hartling L, Bialy LM, Vandermeer B, et al. Epinephrine for bronchiolitis. Cochrane Database Syst Rev 2011; 6: CD003123.

10 Eber E. Treatment of acute viral bronchiolitis. Open Microbiol J 2011; 5: 159-164

11 Lenney W, Boner AL, Bont L, et al. Medicines used in respiratory diseases only seen in children. Eur Respir J 2009; 34: 531-551.

12 Barben J, Kuehni CE, Trachsel D, et al. Management of acute bronchiolitis - can evidence-based guidelines alter clinical practice? Thorax 2008; 63: 1103-1109.

13 Scottish Intercollegiate Guidelines Network. Bronchiolitis in children - a national guideline. Edinburgh, SIGN, 2006.

14 Wainwright C. Acute viral bronchiolitis in children - a very common condition with few therapeutic options. Paediatr Respir Rev 2010; 11: 39-45.

15 Mandelberg A, Tal G, Witzling M, et al. Nebulized 3\% hypertonic saline solution treatment in hospitalized infants with viral bronchiolitis. Chest 2003; 123: 481-487.

16 Tal G, Cesar K, Oron A, et al. Hypertonic saline/epinephrine treatment in hospitalized infants with viral bronchiolitis reduces hospitalization stay: 2 years experience. Isr Med Assoc J 2006; 8: 169-173.

17 Sarrell EM, Tal G, Witzling M, et al. Nebulized 3\% hypertonic saline solution treatment in ambulatory children with viral bronchiolitis decreases symptoms. Chest 2002; 122: 2015-2010.

18 Kuzik BA, Al-Qadhi SA, Kent S, et al. Nebulized hypertonic saline in the treatment of viral bronchiolitis in infants. J Pediatr 2007; 151: 266-270.

19 Grewal S, Ali S, McConnell DW, et al. A randomized trial of nebulized 3\% hypertonic saline with epinephrine in the treatment of acute bronchiolitis in the emergency department. Arch Pediatr Adolesc Med 2009; 163: 1007-1012.

20 Al-Ansari K, Sakran M, Davidson BL, et al. Nebulized 5\% or 3\% hypertonic or $0.9 \%$ saline for treating acute bronchiolitis in infants. J Pediatr 2010; 157: 630-634.

21 Luo Z, Liu E, Luo J, et al. Nebulized hypertonic saline/salbutamol solution treatment in hospitalized children with mild to moderate bronchiolitis. Pediatr Int 2010; 52: 199-202.

22 Luo Z, Fu Z, Liu E, et al. Nebulized hypertonic saline treatment in hospitalized children with moderate to severe viral bronchiolitis. Clin Microbiol Infect 2011; 17: 1829-1833.

23 Ipek IO, Yalcin EU, Sezer RG, et al. The efficacy of nebulized salbutamol, hypertonic saline and salbutamol/ hypertonic saline combination in moderate bronchiolitis. Pulm Pharmacol Ther 2011; 24: 633-637.

24 Miraglia Del Giudice M, Saitta F, Leonardi S, et al. Effectiveness of nebulized hypertonic saline and epinephrine in hospitalized infants with bronchiolitis. Int J Immunopathol Pharmacol 2012; 25: 485-491.

25 Anil AB, Anil M, Saglam AB, et al. High volume normal saline alone is as effective as nebulized salbutamol-normal saline, epinephrine-normal saline, and 3\% saline in mild bronchiolitis. Pediatr Pulmonol 2010; 45: 41-47.

26 Zhang L, Mendoza-Sassi RA, Wainwright C, et al. Nebulised hypertonic saline solution for acute bronchiolitis in infants. Cochrane Database Syst Rev 2013; 7: CD006458.

27 Jacobs JD, Foster M, Wan J, et al. 7\% Hypertonic saline in acute bronchiolitis: a randomized controlled trial. Pediatrics 2014; 133: e8-e13.

28 Florin TA, Shaw KN, Kittick M, et al. Nebulized hypertonic saline for bronchiolitis in the emergency department: a randomized clinical trial. JAMA Pediatr 2014; 168: 664-670.

29 Wu S, Baker C, Lang ME, et al. Nebulized hypertonic saline for bronchiolitis: a randomized clinical trial. JAMA Pediatr 2014; 168: 657-663.

30 Frey U, von Mutius E. The challenge of managing wheezing in infants. N Engl J Med 2009; 360: $2130-2133$. Fitzgerald DA, Kilham HA. Bronchiolitis: assessment and evidence-based management. Med J Aust 2004; 180 : 399-404. Mulholland EK, Olinsky A, Shann FA. Clinical findings and severity of acute bronchiolitis. Lancet 1990; 335: 1259-1261. Wright M, Piedimonte G. Respiratory syncytial virus prevention and therapy: past, present, and future. Pediatr Pulmonol 2011; 46: 324-347.

34 Aherne W, Bird T, Court SD, et al. Pathological changes in virus infections of the lower respiratory tract in children. J Clin Pathol 1970; 23: 7-18.

35 American Academy of Pediatrics. Diagnosis and management of bronchiolitis. Pediatrics 2006; 118: $1774-1793$.

36 Calogero C, Sly PD. Acute viral bronchiolitis: to treat or not to treat-that is the question. J Pediatr 2007; 151: 235-237.

37 Spycher BD, Silverman M, Pescatore AM, et al. Comparison of phenotypes of childhood wheeze and cough in 2 independent cohorts. J Allergy Clin Immunol 2013; 132: 1058-1067.

38 Spycher BD, Silverman M, Brooke AM, et al. Distinguishing phenotypes of childhood wheeze and cough using latent class analysis. Eur Respir J 2008; 31: 974-981.

39 Herr M, Just J, Nikasinovic L, et al. Risk factors and characteristics of respiratory and allergic phenotypes in early childhood. J Allergy Clin Immunol 2012; 130: 389-396. 